\title{
Bionanotechnology and Nanomedicine
}

\author{
P. Bryant Chase, ${ }^{1}$ Seunghun Hong, ${ }^{2}$ Alf Månsson, ${ }^{3}$ and Peng Xiong ${ }^{4}$ \\ ${ }^{1}$ Department of Biological Science, The Florida State University, Tallahassee, FL 32306, USA \\ ${ }^{2}$ Department of Physics and Astronomy, Seoul National University, Seoul 151-742, Republic of Korea \\ ${ }^{3}$ School of Natural Sciences, Linnaeus University, SE-391 82 Kalmar, Sweden \\ ${ }^{4}$ Department of Physics and Integrative NanoScience Institute, The Florida State University, Tallahassee, FL 32306, USA
}

Correspondence should be addressed to P. Bryant Chase, chase@bio.fsu.edu

Received 1 February 2012; Accepted 1 February 2012

Copyright (C) 2012 P. Bryant Chase et al. This is an open access article distributed under the Creative Commons Attribution License, which permits unrestricted use, distribution, and reproduction in any medium, provided the original work is properly cited.

This special issue contains contributions from the broad interdisciplinary fields of bionanotechnology and nanomedicine. Nanotechnology has great promise in biology and medicine. This includes new approaches to fundamental studies, improved methods for detection of protein or nucleic acid-based biomarkers of disease, and new ways to administer drugs or vaccines or enhancing their effects. The tools of nanotechnology provide new insights into mechanisms of normal biological functions and diseases. Novel nanotechnology-based imaging methods reveal structural and functional information at progressively higher levels of resolution, both in vitro, in cells and in organisms. Molecular components of biological systems on their own can be often viewed as nanoscale machines with functions that have been tuned through evolution and with design principles often based on self-assembly and self-organization phenomena. These biological nanomachines can be incorporated into micro- and nanofabricated devices, a merger that yields novel structures and functionalities.

\section{Acknowledgments}

The editors of this special issue on bionanotechnology and nanomedicine sincerely thank the authors for providing original research and review contributions that will be of interest to a broad array of nanoscience researchers as well as biologists and biomedical scientists who wish to explore recent developments in the "nano" arena. Their contributions describe novel insights into biology and medicine made possible by nanotechnology, new nanotechnology devices that have applications to biology and/or medicine, and perspectives on development of these fields, combined with the promises and challenges that lie ahead. It is our hope that this special issue will not only provide insights but also stimulate new ideas and advances.

\section{P. Bryant Chase Seunghun Hong Alf Månsson Peng Xiong}



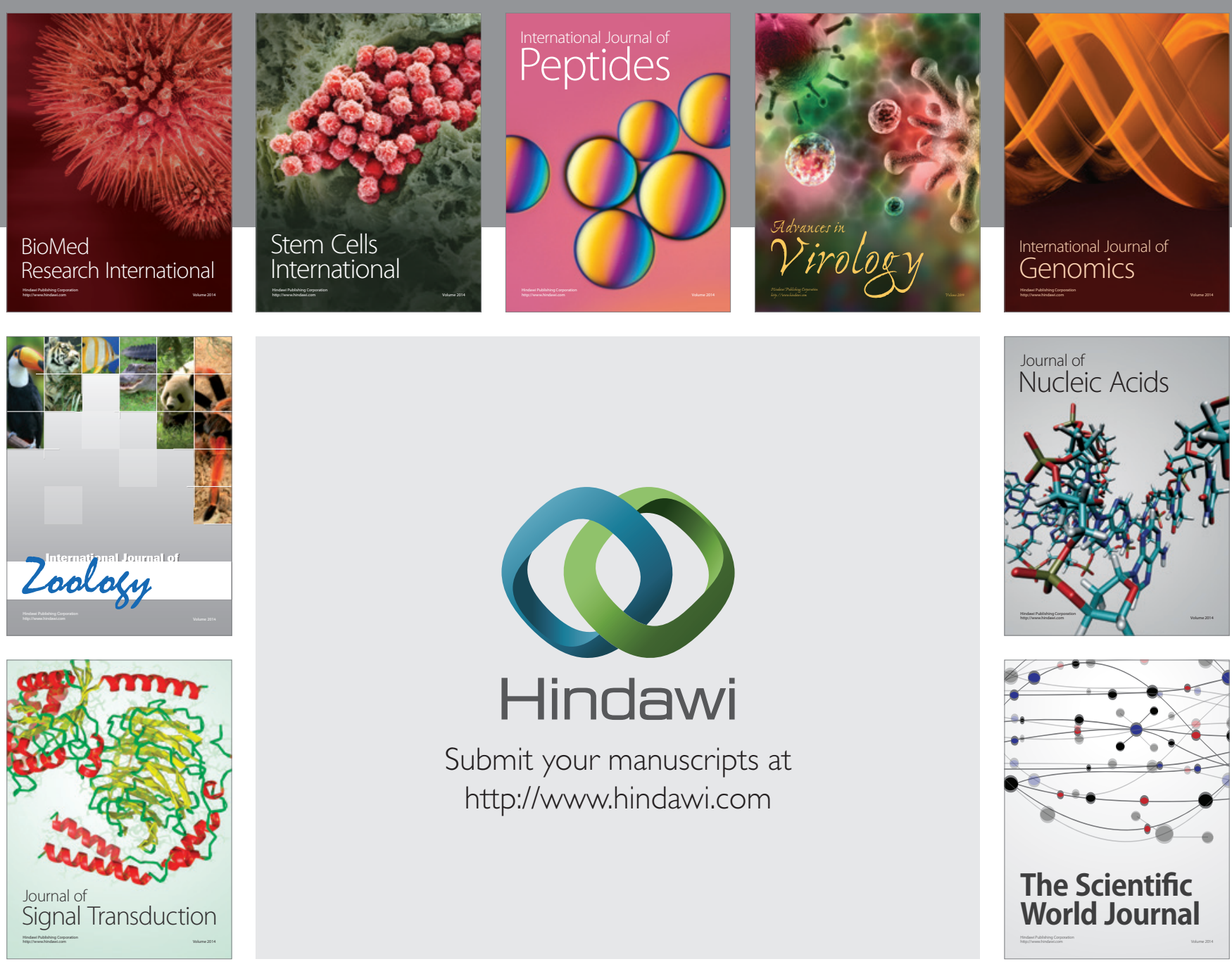

Submit your manuscripts at

http://www.hindawi.com
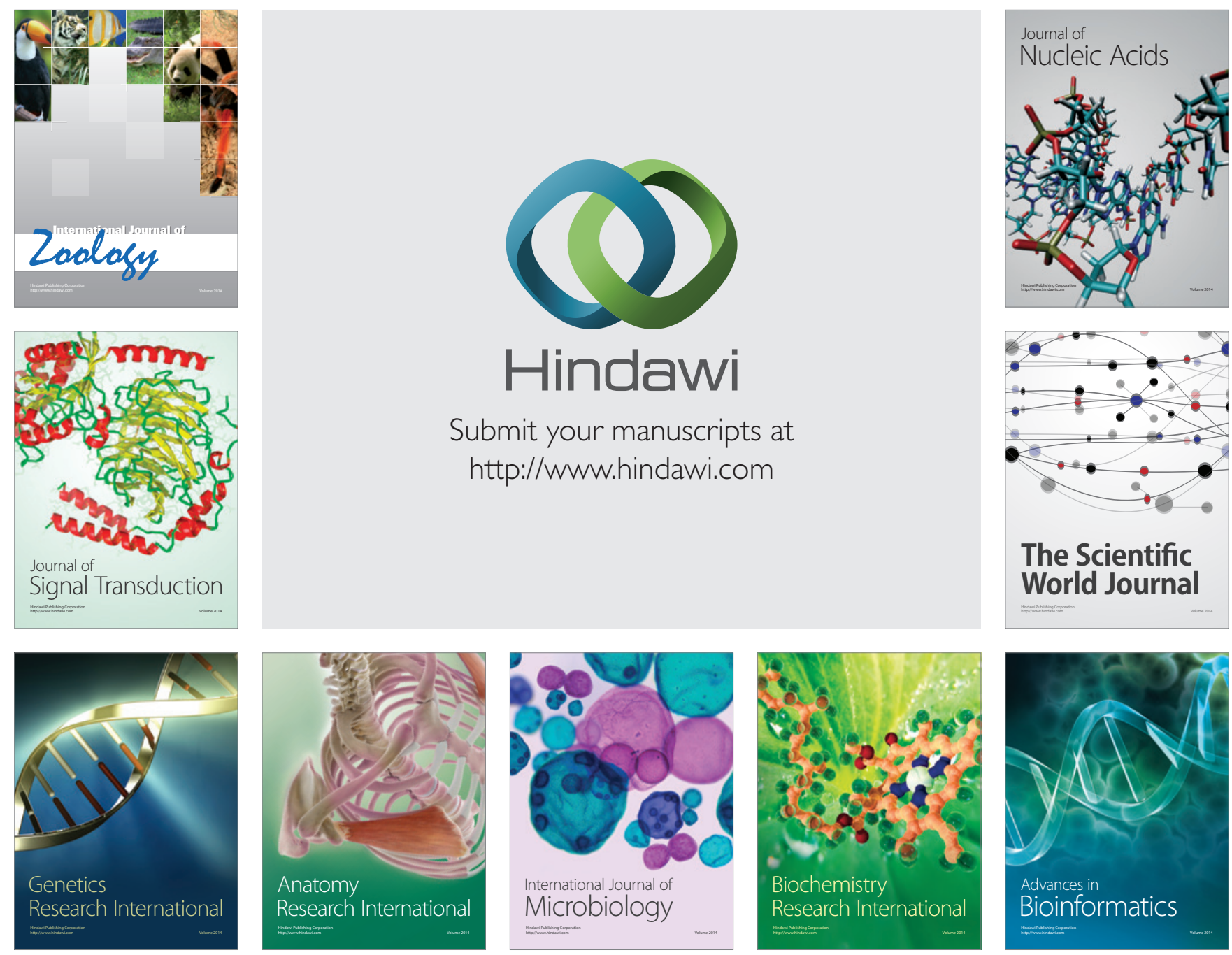

The Scientific World Journal
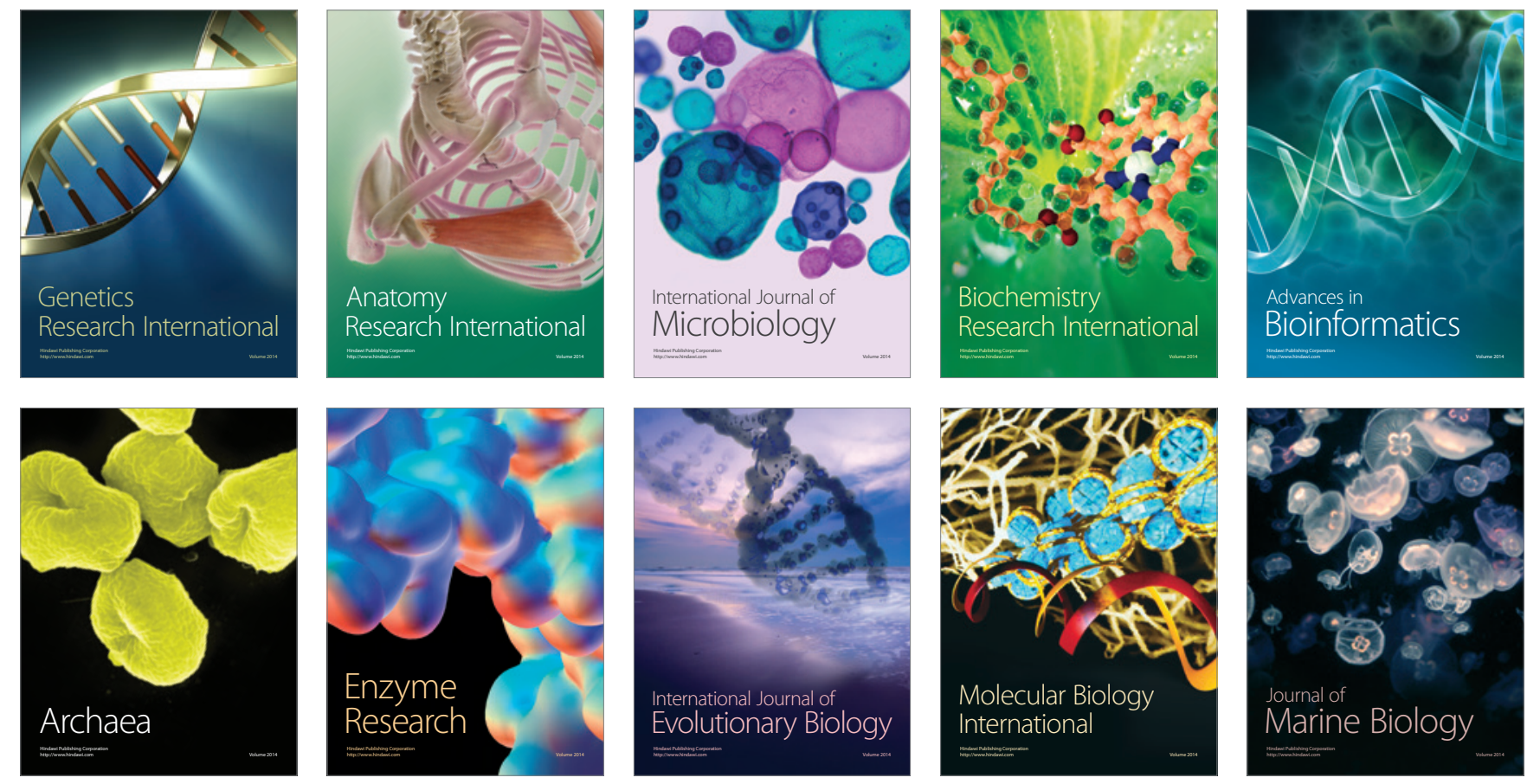